\title{
Surgical Site Infection among Women Post Cesarean Section: An Integrative Review
}

\author{
Shinta Novelia ${ }^{1}$, Wipa Sae $\mathrm{Sia}^{2}$, Praneed Songwathana ${ }^{3}$ \\ ${ }^{1}$ Midwifery Department, Faculty of Health Science, Universitas Nasional, Indonesia \\ ${ }^{2,3}$ Department of Surgical Nursing, Faculty of Nursing, \\ Prince of Songkla University, Thailand \\ Corresponding Author: Shinta Novelia (cdrchinta@yahoo.com)
}

\begin{abstract}
Background: Surgical site infection (SSI) in cesarean section (CS) is a major cause of prolonged hospital stay and resource consumption, and causes morbidity and mortality for the mother and the baby.

Purpose: This literature review aimed to assess and identify risk factors, interventions, and prevention strategies of SSI for women post CS especially the obese women.

Methods: An integrative literature review was conducted by employing the databases of PubMed, ProQuest, Science Direct, Wiley online library, and Google scholar from 1999 to 2015. This review identified the studies conducted either in women post-CS or obese women post CS.

Results: A total of 58 articles were found, and 14 articles met the criteria. The risk factors of CS-SSI were classified into extrinsic and intrinsic factors. The intrinsic factors include limited mobility, poor nutrition, and comorbidity (diabetes) while the extrinsic factors include surgical technique, skin closure methods, prophylactic antibiotic, and the use of drains. Poor nutrition, diabetes, and limited mobility were the common factors found in obese women undergoing CS. Maintaining nutritional status and controlling blood glucose were proposed to prevent CS-SSI among obese women post-CS.

Conclusions: Nurses should have adequate knowledge about the risk factors of CS-SSI to assess the risk factors of CS-SSI especially in obese women. The intervention of CSSSI might need a bundle of interventions which consist of pre-operative and postoperative prevention strategies.
\end{abstract}

Keywords: Obese women; wound infection; surgical site infection; cesarean section

\section{BACKGROUND}

Obesity in reproductive health significantly increases the rate of caesarean section (CS) (Machado, 2012). The World Health Organization (WHO) estimates caesarean labor to be approximately $5-15 \%$ for every country (Suryati, 2013). However, the CS procedure was increased by $30 \%$ of all hospital births in Australia and New Zealand (Brown et al., 2013). Obesity can result in serious post-operative complications for women post CS such as SSI (Anderson, Chaboyer, \& Gillespie, 2013). Surgical site infection (SSI) is a wound infection that occurs following surgery and usually expands within 30 days of 
surgery, SSI can presence for one year after surgery in some patients with a prosthetic implant (Harrington, 2014). Studies that have been conducted in some developing countries found the incidence of CS-SSI as follows: $12.5 \%$ CS-SSI in Nigeria, $29.38 \%$ CS-SSI in Oman, and 9.6\% CS-SSI in Thailand (Dhar et al., 2014; Ezechi, Edet, Akinlade, Gab-Okafor, \& Herbertson, 2009; Kasatpibal, Jamulitrat, Chongsuvivatwong, \& Surgical Site Infection Study Group, 2005). Studies conducted in England, USA, and Australia found the CS-SSI prevalence of 51\% in England's obese population, $13.5 \%$ in USA obese population, and 10\% in Australia general population (Anderson et al., 2013; Dryden et al., 2014; Johnson, Young, \& Reilly, 2006). There are limited studies conducted regarding the incidence of CS-SSI among obese and general population in the same setting.

The incidence of CS-SSI does not seem different between the developed and developing country. Even though the system of infection control in the developed country is good, there are some factors that might influence the high rate of CS-SSI. The common organisms related to CS-SSI are Staphylococcus aureus and Escherichia coli. The administration of antibiotic prophylaxis is recommended to reduce the incidence of CSSSI. A study conducted in England revealed that the used of antibiotic prophylaxis was poor (Ng et al., 2015).

CS-SSI is a major cause of prolonged hospital stay and resource consumption and causes morbidity and mortality for the mother and the baby (Alexander \& Liston, 2006; Baugh, Zuelzer, Meador, \& Blankenship, 2007; Harrington, 2014). An evidence-based guideline is required to ensure that nurses have an understanding of the risk factors of CS-SSI and how women either with normal weight or overweight can impact on CSSSI. Thus, nurses need to identify the risk factors and determine the best available intervention to decrease CS-SSI for developing targeted interventions. Therefore, the purpose of this report is to review the studies on SSI among women post CS either with normal weight or overweight to determine the best available intervention to decrease its occurrences.

\section{PURPOSE}

This research aimed to assess and identify the risk factors, interventions, and prevention strategies of SSI for women post CS especially the obese women.

\section{METHODS}

An integrative review was undertaken, as this methodology offers a synthesis of knowledge and applicability of results of significant studies to practice (Souza, Silva, \& Carvalho, 2010). This study used online databases of PubMed, ProQuest, Google Scholar, Science Direct, and Wiley online Library. Different combinations of search terms related to SSI in CS were employed for searching relevant articles published through the year of 1992-2015. The keywords and search terms used were based on the PICO abbreviations: $\mathrm{P}=$ obese women, wound infection; surgical site infection, cesarean section; I= intervention; $\mathrm{C}=-; \mathrm{O}=$ surgical site infection (JBI, 2014).

The search was limited to the articles published in English. The studies selected were experimental studies, quasi-experimental studies, observational analytic studies, 
observational descriptive studies, and guidelines. A total of 58 articles were found. Fourteen articles met the criteria and were related to the study objectives, while 44 other articles did not meet the criteria. It was because the studies were conducted in general surgery and were not related to the study objectives (Figure 1).

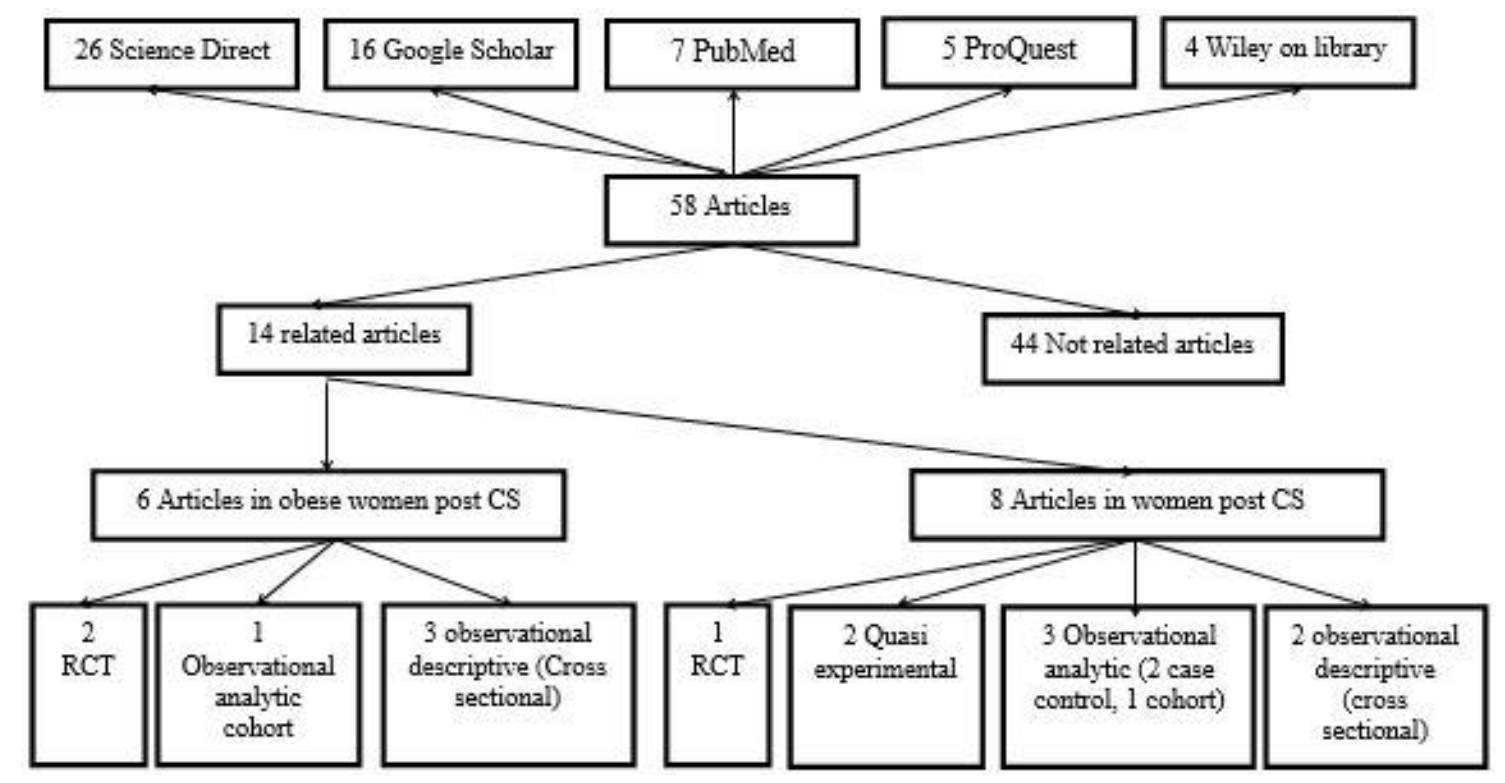

Figure 1. Literature search process and search result

The relevant articles were graded by using the grading of recommendations based on the Joanna Briggs Institute for Evidence-Based Nursing and Midwifery (JBI) 2014 (JBI, 2014). Data were extracted into a created table. The items in the table consisted of authors, year of publication, results, sample, and the level of evidence (Table 1).

Table 1. Table of evidence

\begin{tabular}{|c|c|c|c|c|c|c|c|}
\hline \multirow[t]{2}{*}{ No } & \multirow[t]{2}{*}{ Author (s)/ year } & \multicolumn{3}{|c|}{ Results } & \multicolumn{2}{|c|}{ Sample } & \multirow{2}{*}{$\begin{array}{l}\text { Level of } \\
\text { evidence }\end{array}$} \\
\hline & & $\begin{array}{l}\text { Intrinsic } \\
\text { factor }\end{array}$ & $\begin{array}{l}\text { Extrinsic } \\
\text { factor }\end{array}$ & Intervention & Obese & $\begin{array}{c}\text { Not } \\
\text { defined }\end{array}$ & \\
\hline 1 & Nobbs\& Crozier., 2011 & $\sqrt{ }$ & $\sqrt{ }$ & & $\sqrt{ }$ & & $3 b$ \\
\hline 2 & Thomburg et al., 2012 & $\sqrt{ }$ & $\sqrt{ }$ & & $\sqrt{ }$ & & $4 \mathrm{~b}$ \\
\hline 3 & Dryden et al., 2014 & & & $\sqrt{ }$ & & $\sqrt{ }$ & $4 \mathrm{~b}$ \\
\hline 4 & Yeeeles et al., 2014 & & & $\sqrt{ }$ & $\sqrt{ }$ & & $3 e$ \\
\hline 5 & Nikpour et al., 2014 & & & $\sqrt{ }$ & & $\sqrt{ }$ & $1 \mathrm{c}$ \\
\hline 6 & $\begin{array}{l}\text { Farret, da Silva Montiro, } \\
\text { Riche, \&Antonello, } 2014\end{array}$ & & $\sqrt{ }$ & $\sqrt{ }$ & & $\sqrt{ }$ & $3 d$ \\
\hline 7 & Dhar et al., 2014 & $\sqrt{ }$ & & & & $\sqrt{ }$ & $4 \mathrm{~b}$ \\
\hline 8 & Rauk., 2010 & & & $\sqrt{ }$ & & $\sqrt{ }$ & $2 \mathrm{~d}$ \\
\hline 9 & $\begin{array}{l}\text { Opoien, Valbo, Grinde- } \\
\text { Andersen, \&Wakberg, } 2007\end{array}$ & $\sqrt{ }$ & & $\sqrt{ }$ & & $\sqrt{ }$ & $3 \mathrm{e}$ \\
\hline 10 & $\mathrm{Ng}$ et al., 2015 & & & $\sqrt{ }$ & & $\sqrt{ }$ & $2 \mathrm{c}$ \\
\hline 11 & Ramsey et al., 2005 & & & $\sqrt{ }$ & $\sqrt{ }$ & & $1 \mathrm{c}$ \\
\hline 12 & Olsen et al., 2014 & $\sqrt{ }$ & $\sqrt{ }$ & & & $\sqrt{ }$ & $3 d$ \\
\hline 13 & Ibrahim et al., 2014 & & & $\sqrt{ }$ & $\sqrt{ }$ & & $1 \mathrm{c}$ \\
\hline 14 & Wakk et al., 2003 & $\sqrt{ }$ & $\sqrt{ }$ & & $\sqrt{ }$ & & $4 \mathrm{~b}$ \\
\hline
\end{tabular}




\section{RESULTS \\ Risk factors}

There are many risk factors of CS-SSI, which are defined as extrinsic and intrinsic factors. Several intrinsic factors of CS-SSI were found in women post-CS. Those were premature rupture of membrane, preeclampsia, obesity, mobility, poor nutrition, and comorbidity, such as diabetes (Dhar et al., 2014; Nobbs \& Crozier, 2011; Thornburg et al., 2012). Diabetes is the common intrinsic factors both for normal women and obese women post-SC. On the other hand, some extrinsic factors were also identified in the literature in women post-CS either normal or overweight. The extrinsic factors were the unscheduled of CS, the use of drain, length of surgery, type of skin preparation, surgical technique, skin closure methods, prophylactic antibiotic, and the use of drains (Hopkins, \& Smaill, 2012; Johnson, Young, \& Reilly, 2006; Nobbs, \& Crozier, 2011; Olsen et al., 2008; Thornburg et al., 2012; Vermillion, Lamoutte, Soper, \& Verdeja, 2000).

\section{Interventions and preventions of the CS-SSI.}

Some interventions had been found to prevent CS-SSI either in pre-operative or postoperative care. The pre-operative prevention strategies included the pre-operative skin preparation, staff education, and administration of prophylaxis antibiotic. Meanwhile, the post-operative prevention strategy was the use of appropriate dressing material.

\section{DISCUSSION}

\section{Risk factors}

Some risk factors contributing to SSI were similar among both the women post CS with normal and overweight. The common intrinsic factor is diabetes. Diabetes was found to be an intrinsic factor which contributed to SSI in women post CS either normal or overweight. A study conducted in Oman found that there was a significant association between diabetes and SSI in women post CS $(p=.001)$ and women with diabetes were three times more likely to develop SSI ( $O R=3.09)$ (Kasatpibal et al., 2005). Likewise, a study carried out by Nobbs and Crozier (Nobbs \& Crozier, 2011) found that the common comorbidity which contributed to pregnant women with obesity was diabetes. However, poor nutrition and limited mobility were the only factors found in obese women undergoing CS. Nutritional deficiency was the common factor to consider when analyzing wound healing and SSI in obese women (Mangram, Horan, Pearson, Silver, \& Jarvis, 1999). The lack of nutrition, such as protein or carbohydrates, which will be translated into the used energy may be disturbing the process of wound healing. The severe protein-calorie malnutrition was associated with SSI for some types of operation including CS (De Vivo et al., 2010). Moreover, mobility is very important for the women undergoing surgery because it decreases other risks, which strongly linked to obesity, such as thromboembolism, pressure ulcers, and wound dehiscence (Alexander \& Liston, 2006; Baugh et al., 2007; Derbyshire, Davies, Costarelli, \& Dettmar, 2006; Robinson, O'Connell, Joseph, \& McLeod, 2005;). Women with obesity have limited mobility. The limited mobility may disturb blood circulation and influence the wound healing process. If the wound healing is delayed within 30 days, it is defined as SSI.

The other intrinsic risk factors were pre-eclampsia and premature rupture of membrane. A study conducted by Dhar et al (Dhar et al., 2014) found that there was a significant association between hypertension/preeclampsia and SSI $(p=.007)$. Women who had 
hypertension and preeclampsia were three times more likely to develop SSI compared to women without these conditions $(O R=3.19)$. Likewise, premature rupture of the membrane is an obstetric-related risk factor of both intrinsic and extrinsic that contributes to SSI in women post-CS. Research has identified that there was a significant association between the duration of membrane rupture (interval between rupture membrane and delivery) and the incidence of SSI $(p=.003)$ (Farret, Dalle, Monteiro, Riche, \& Antonello, 2015).

The similarity among the extrinsic factor in both women post CS with normal and overweight is the technique of skin closure. The stapled skin closure and the subcuticular suture technique are not recommended. A study conducted by Ibrahim et al (Ibrahim, Moustafa, Al-Hamid, \& Hussein, 2014) found that obese women who had an interrupted mattress suture developed SSI less than those who had a subcuticular suture. Some techniques were found for allowing more rapid closure and reducing SSI; these included the use of staples or adhesive acrylate glues (NICE, 2008). A study conducted by Olsen et al (Olsen et al., 2008) also found that the use of staples for skin closure was associated with a marginally increased risk of SSI in women post CS. However, more research is needed to explore the suture technique and suture material in CS. On the other hand, the different extrinsic factors only found in the obese women were surgical techniques, the use of a drain, and prophylactic antibiotics. Wall et al found that among women undergoing a vertical incision, $34.6 \%$ experienced SSI compared to $9 \%$ of those with a transverse incision; a difference that remained evident when only wound infections were taken into consideration (19\% against 7\%) (Wall, Deucy, Glantz, \& Pressman, 2003). Similarly, a study conducted by Thornburg et al found that there was a significant association between the vertical incision and the wound infection $(p=0.01)$ (Thornburg et al., 2012). In conclusion, the transverse incision is recommended to reduce CS-SSI. The use of drain contributes to developing SSI in obese women postCS. The use of drain is not recommended for obese women post-CS. A previous study found that the use of subcuticular drain was associated with SSI in obese women post CS ( $p<.001)$ (Thornburg et al., 2012). Another study conducted in America found that the additional use of a subcutaneous drain along with a standard subcutaneous suture reapproximation technique was not effective for the prevention of wound complications (Ramsey et al., 2005). Furthermore, the use of prophylactic antibiotics is not statistically significant with the incidence of SSI. Two studies (Derbyshire et al., 2006; Yeeles, Trinick, Childs, Soltani, \& Farrell, 2014) found that there was no statistically significant difference of SSI between patients who were given antibiotics and who were not in the emergency or elective CS. On the other hand, the latest study ( $\mathrm{Ng}$ et al., 2015) found that the optimal timing of antibiotic prophylaxis is important to reduce CS-SSI, especially when a prophylactic antibiotic is given within 60 minutes of incision vs. after cord clamping. In conclusion, it needs further research to ensure the appropriate time of giving antibiotics and the type of antibiotics that are used in CS to reduce SSI.

The other extrinsic factors were unscheduled of CS, the length of surgery, and the type of skin preparation. Unscheduled of CS was found to be contributed to SSI in women post-CS. Two studies found that patients who underwent scheduled CS tended toward fewer wound complication including SSI, compared to the cesarean during labor (unscheduled CS) (Ng et al., 2015; Thornburg et al., 2012). The length of surgery also 
contributed to SSI. Two studies found that there was an association between a longer duration of operation and SSI in women post CS (Kristian Opoien, Valbo, GrindeAndersen, \& Walberg, 2007; Vermillion et al., 2000). Also, hair removal of preoperative preparation skin was recognized to be useful in pre-operative procedures because it facilitated the skin mark, described the orientation for the surgeon, and accelerated closure (Harrop et al., 2012). National Institute for Health and Clinical Excellence (NICE) recommended avoiding hair removal shaving (NICE, 2008). If the hair has to be removed, use the electric clippers with a single use head on the day of surgery (NICE, 2008).

\section{Interventions and preventions of the CS-SSI.}

Some interventions to prevent the CS-SSI were pre-operative skin preparation, staff education, administration of a prophylactic antibiotic, and dressing. A prospective cohort study (Graling \& Vasaly, 2013) found that chlorhexidine gluconate compared with iodine alone resulted in lower rates of bacterial growth at 18 hours after CS. It can be concluded that chlorhexidine gluconate is more recommended than iodine alone to prevent CS-SSI. Moreover, regarding the staff education, in a study by Rauk (2010), the staff education and training were applied as the bundle of intervention, including preoperative skin preparation with $\mathrm{CHG}$, intraoperative skin preparation using $\mathrm{CHG}$ with alcohol, and management of instrument sterilization. The result found a significant reduction in the overall SSI rate after the intervention. However, it cannot be concluded that the staff education was effective to reduce SSI because it was a group intervention. In term of the administration of a prophylactic antibiotic, a study found that the early administration of antibiotics, 2 to 24 hours into the pre-operative period was associated with the lowest risk of SSI (Skjeldestad, Bjornholt, Gran, \& Erisken, 2015). In addition, it also found that hospitals that provided antibiotic prophylaxis to all women undergoing CS had reduced rates of superficial SSIs among the planned CS (Skjeldestad, Bjornholt, Gran, \& Erisken, 2015). Also, using the appropriate dressing material is required for the prevention of SSI among women undergoing CS. A study conducted in England found that using biologically modified honey as wound dressing material reduced CS-SSI (Dryden et al., 2014). Similarly, Nikpour et al found that biologically modified honey is effective to promote wound healing status to reduce SSI and recommended because it is a natural product with rare side effects and low cost (Nikpour, Shirvani, Azadbakht, Zanjani, \& Mousavi, 2014).

From the analyses, it can be concluded that CS-SSI may not require only a single intervention, but could need a bundle of interventions which consist of pre-operative and post-operative prevention strategies. Since diabetes was the common factors, maintaining nutritional status and controlling blood glucose might be necessary to prevent SSI among obese women post-CS. Nurses should have adequate knowledge about the risk factors of CS-SSI. Systematic nursing intervention is necessary to be implemented to prevent CS-SSI such as assessing the risk factors of CS-SSI especially in obese women and using the evidence-based practice of CS-SSI prevention. The result of this study could be used as an evidence-based of CS-SSI prevention strategies and could improve nursing care to prevent CS-SSI. 
The strength of this review was that the articles reviewed have a moderate level (4b) to a high level of evidence (1c) (JBI, 2014), and some intervention studies have a large sample size. In addition, the result of this study could be used as the evidence-based CSSSI prevention strategies to improve nursing care on preventing CS-SSI. However, there has been a limited study conducted on the intervention of CS-SSI in general population and obese population. The limitation of this review included the time-range of the study has gone far back as 1999 because studies and guidelines conducted in recent years were too limited.

\section{CONCLUSIONS}

The CS procedure is commonly found to be associated with significant infectious morbidity involving SSI either in the general or obese population. Nurses should have adequate knowledge about the risk factors of CS-SSI. CS-SSI may not require only a single intervention but could need a bundle of interventions which consist of preoperative and post-operative prevention strategies. Further studies to explore the interventions to reduce or prevent SSI for obese women undergoing CS are needed.

\section{REFERENCES}

Alexander, C. I., \& Liston, W. A. (2006). Review article: Operating on the obese woman-a review. British Journal of Obstetrics and Gynaecology: An International Journal of Obstetrics \& Gynaecology,113(10), 1167-1172. doi:10.1111/j.1471-0528.2006.01073.x

Anderson, V., Chaboyer, W., \& Gillespie, B. (2013). The relationship between obesity and surgical site infections in women undergoing caesarean sections: An integrative review. Midwifery, 29(12), 1331-1338. doi:10.1016/j.midw.2012.12.012

Baugh, N., Zuelzer, H., Meador, J., \& Blankenship, J. (2007). Wounds in surgical patients who are obese.The American Journal of Nursing, 107(6), 40-50. doi: 10.1097/01.NAJ.0000271848.07721.24.

Brown, J., Thompson, M., Sinnya, S., Jeffery, A., de Costa, C., Woods, C., ...\& Raulli, A. (2013). Pre-incision antibiotic prophylaxis reduces the incidence of postcaesarean surgical site infection. Journal of Hospital Infection, 83(1), 68-70. doi:10.1016/j.jhin.2012.08.014

Derbyshire, E., Davies, J., Costarelli, V., \& Dettmar, P. (2006). Prepregnancy body mass index and dietary intake in the first trimester of pregnancy. Journal of human nutrition and dietetics, 19(4), 267-273.

De Vivo, A., Mancuso, A., Giacobbe, A., Priolo, A., De Dominici, R., \& Maggio Savasta, L. (2010). Wound length and corticosteroid administration as risk factors for surgical site complications following cesarean section. Acta Obstetricia et Gynecologica Scandinavica, 89(3), 355-359. doi: 10.3109/00016340903568175

Dhar, H., Al-Busaidi, I., Rathi, B., Nimre, E. A., Sachdeva, V., \& Hamdi, I. (2014). A study of post-caesarean section wound infections in a regional referral hospital, Oman. Sultan Qaboos University Medical Journal, 14(2), 211-217.

Dryden, M., Goddard, C., Madadi, A., Heard, M., Saeed, K., \& Cooke, J. (2014). Using antimicrobial surgihoney to prevent caesarean wound infection. British Journal of Midwifery, 22(2), 111-115. 
Ezechi, O. C., Edet, A., Akinlade, H., Gab-Okafor, C. V., \& Herbertson, E. (2009). Incidence and risk factors for caesarean wound infection in Lagos Nigeria. Biomed Central Research Notes, 2(1), 1-5. doi:10.1186/1756-0500-2-186

Farret, T. C. F., Dallé, J., Monteiro, V. D. S., Riche, C. V. W., \& Antonello, V. S. (2015). Risk factors for surgical site infection following cesarean section in a Brazilian Women's Hospital: A case-control study. Brazilian Journal of Infectious Diseases, 19(2), 113-117. doi:10.1016/j.bjid.2014.09.009

Graling, P. R., \& Vasaly, F. W. (2013). Effectiveness of 2\% CHG cloth bathing for reducing surgical site infections. Association of Peri Operative Registered Nurses Journal, 97(5), 547-551. doi: 10.1016/j.aorn.2013.02.009

Harrington, P. (2014). Prevention of surgical site infection. Nursing Standard, 28(48), 50-58.

Harrop, J. S., Styliaras, J. C., Ooi, Y. C., Radcliff, K. E., Vaccaro, A. R., \& Wu, C. (2012). Contributing factors to surgical site infections. Journal of the American Academy of Orthopaedic Surgeons, 20(2), 94-101. doi:10.5435/JAAOS-20-02094

Hopkins, L., \& Smaill, F. M. (2012). Antibiotic prophylaxis regimens and drugs for cesarean section. The Cochrane Library. Retrieved from http://apps.who.int/rhl/reviews/CD001136.pdf

Ibrahim, M. I., Moustafa, G. F., Al-Hamid, A. S. A., \& Hussein, M. R. (2014). Superficial incisional surgical site infection rate after cesarean section in obese women: A randomized controlled trial of subcuticular versus interrupted skin suturing. Archives of Gynecology and Obstetrics, 289(5), 981-986. doi:10.1007/s00404-013-3098-z

Joanna Briggs Institution, (2014). Joanna Briggs Institute Reviewers' Manual. Retrieved from: http://joannabriggs.org/assets/docs/sumari/ReviewersManual2014.pdf

Johnson, A., Young, D., \& Reilly, J. (2006). Caesarean section surgical site infection surveillance.Journal of Hospital Infection, 64(1), 30-35. doi:10.1016/j.jhin.2006.03.020

Kasatpibal, N., Jamulitrat, S., Chongsuvivatwong, V., \& Surgical Site Infection Study Group. (2005). Standardized incidence rates of surgical site infection: A multicenter study in Thailand. American Journal of Infection Control,33(10), 587-594. doi:10.1016/j.ajic.2004.11.012

Kristian Opoien, H., Valbø, A., Grinde-Andersen, A., \& Walberg, M. (2007). Postcesarean surgical site infections according to CDC standards: rates and risk factors. A prospective cohort study. Acta Obstetricia et Gynecologica Scandinavica, 86(9), 1097-1102.

Machado, L. S. (2012). Cesarean section in morbidly obese parturients: practical implications and complications. North American Journal of Medical Sciences, 4(1), 13.

Mangram, A. J., Horan, T. C., Pearson, M. L., Silver, L. C., \& Jarvis, W. R. (1999). Guideline for prevention of surgical site infection, 1999. Hospital Infection Control Practices Advisory Committee. Infection Control Hospital Epidemiology, 20, 250-278.

Ng, W., Brown, A., Alexander, D., Ho, M. F., Kerr, B., Amato, M., \& Katz, K. (2015). A multifaceted prevention program to reduce infection after cesarean section: 
Interventions assessed using an intensive post discharge surveillance system. American Journal of Infection Control.43(8). 805-809. doi: 10.1016/j.ajic.2015.04.001

Nobbs, S., \& Crozier, K. (2011). Wound management in obese women following caesarean section. British Journal of Midwifery, 19(3), 150-156. doi: 10.12968/bjom.2011.19.3.150

National Institute for Health and Clinical Excellence [NICE].(2008). Surgical site infection. Retrieved from https://www.nice.org.uk/guidance/CG74

Nikpour, M., Shirvani, M. A., Azadbakht, M., Zanjani, R., \& Mousavi, E. (2014).The effect of honey gel on abdominal wound healing in cesarean section: A triple blind randomized clinical trial. Oman Medical Journal, 29(4), 255.doi: 10.5001/omj.2014.68

Olsen, M. A., Butler, A. M., Willers, D. M., Devkota, P., Gross, G. A., \& Fraser, V. J. (2008). Risk factors for surgical site infection after low transverse cesarean section. Infection Control, 29(06), 477-484.

Ramsey, P. S., White, A. M., Guinn, D. A., Lu, G. C., Ramin, S. M., Davies, J. K., ...\& Hauth, J. C. (2005). Subcutaneous tissue reapproximation, alone or in combination with drain, in obese women undergoing cesarean delivery.Obstetrics \& Gynecology, 105, 967-973. doi:10.1097/01.AOG.0000158866.68311.d1

Rauk, P. N. (2010). Educational intervention, revised instrument sterilization methods, and comprehensive preoperative skin preparation protocol reduce cesarean section surgical site infections. American Journal of Infection Control, 38(4), 319-323. doi:10.1016.ajic.2009.10.004

Robinson, H. E., O’Connell, C. M., Joseph, K. S., \& McLeod, N. L. (2005). Maternal outcomes in pregnancies complicated by obesity. Obstetrics \& Gynecology, 106(6), 1357-1364. doi:10.1097/01.AOG.0000188387.88032.41

Skjeldestad, F. E., Bjornholt, J. V., Gran, J. M., \& Erisken, H. M. (2015). The effect of antibiotic prophylaxis guidelines on surgical-site infections associated with cesarean delivery. International Journal of Gynecology \& Obstetrics, 128(2), 126130. doi: 0.1016/j.ijgo.2014.08.018

Souza, M. T. D., Silva, M. D. D., \& Carvalho, R. D. (2010). Integrative review: what is it? How to do it?. Einstein (São Paulo), 8(1), 102-106.

Suryati, T. (2013). Analisis lanjut data Riskesdas (2010) persentase operasi caesaria di Indonesia melebihi standard maksimal, apakah sesuai indikasi medis? [Percentage of sectio caesaria in Indonesia is passad the maximum standard, is it in accordance to medical indication?]. Health Systems Research Bulletin, 15. Retrieved from http://bpk.litbang.depkes.go.id/

Thornburg, L. L., Linder, M. A., Durie, D. E., Walker, B., Pressman, E. K., \& Glantz, J. C. (2012). Risk factors for wound complications in morbidly obese women undergoing primary cesarean delivery. Journal of Maternal-Fetal and Neonatal Medicine,25(9), 1544-1548. doi: 10.3109/14767058.2011.653422

Tran, T. S., Jamulitrat, S., Chongsuvivatwong, V., \& Geater, A. (2000).Risk factors for post cesarean surgical site infection.Obstetrics \& Gynecology, 95(3), 367-371.

Vermillion, S. T., Lamoutte, C., Soper, D. E., \& Verdeja, A. (2000). Wound infection after cesarean: effect of subcutaneous tissue thickness. Obstetrics \& Gynecology, 95(6), 923-926. 
Wall, P. D., Deucy, E. E., Glantz, J. C., \& Pressman, E. K. (2003). Vertical skin incisions and wound complications in the obese parturient. Obstetrics \& Gynecology, 102(5), 952-956.

Yeeles, H., Trinick, S., Childs, C., Soltani, H., \& Farrell, T. (2014). Postpartum infection in morbidly obese women after c-section: Does early prophylactic oral antibiotic use make a difference. Journal of Women's Health Care, 3(172), 21670420. doi:10.4236/ojog.2014.49077 